\title{
Knowledge, attitudes and practices related to dietary salt intake among adults in North India
}

\author{
Vandana Garg ${ }^{1}$, Roopa Shivashankar ${ }^{1}$, Dimple Kondal ${ }^{2}$, Shreeparna Ghosh ${ }^{3}$, \\ Shweta Khandelwal ${ }^{2}$, Ruby Gupta ${ }^{2}$, Anand Krishnan ${ }^{4}$, Ritvik Amarchand ${ }^{4}$, \\ Dorairaj Prabhakaran ${ }^{1,2}$ and Sailesh Mohan ${ }^{1,2, *}$ \\ ${ }^{1}$ Centre for Chronic Disease Control, New Delhi, India: ${ }^{2}$ Centre for Chronic Conditions and Injuries (CCCI), Public \\ Health Foundation of India, 6th Floor, Plot no. 47, Sector 44, Gurugram 122002, Haryana, India: ${ }^{3}$ IPE Global, New \\ Delhi, India: ${ }^{4}$ All India Institute of Medical Sciences, New Delhi, India
}

Submitted 9 May 2018: Final revision received 23 September 2018: Accepted 5 November 2018: First published online 28 December 2018

\begin{abstract}
Objective: To assess the knowledge, attitudes and practices related to salt consumption among adults in rural and urban North India.

Design: Data for the study were obtained from a community-based cross-sectional survey using an interviewer-administered questionnaire and $24 \mathrm{~h}$ urine samples. Setting: Data collection was conducted during March-October 2012 in rural Haryana and urban Delhi in North India.

Participants: Adults ( $n$ 1635) aged $\geq 20$ years (701 in rural Haryana; 934 in urban Delhi).

Results: Twenty-four per cent of rural and $40.5 \%$ of urban participants knew that a high-salt diet causes high blood pressure. Nearly one-fifth of both rural and urban participants knew that there should be a maximum daily limit for consumption of salt. In rural and urban areas, 46.6 and $45.1 \%$, respectively, perceived it important to reduce the salt content of their diet; however, only 3.7 and $10.2 \%$, respectively, reported taking some actions. Participants reported they were consuming 'too little salt', 'just the right amount of salt' or 'too much salt', but their corresponding mean (95\% CI) actual salt consumption ( $\mathrm{g} / \mathrm{d}$; as measured by $24 \mathrm{~h}$ urinary $\mathrm{Na}$ excretion) was higher, especially among rural participants (rural: 9.2 (8.13, 10.22), 8.5 (8.19, $8.77)$ or $8.4(7 \cdot 72,8.99)$; urban: $5 \cdot 6(4 \cdot 67,6.57), 5 \cdot 7(5 \cdot 32,6 \cdot 01)$ or $4.6(4 \cdot 10,5 \cdot 14)$, respectively).

Conclusions: Knowledge about the deleterious health impact of excess salt consumption is low in this population. Tailored public education for salt reduction is warranted with a particular focus on rural residents.
\end{abstract}

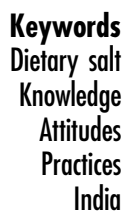

Excess $\mathrm{Na}$ or salt consumption is linked to $17-30 \%$ of hypertension globally and hypertension is one of the top ten risk factors of mortality and $\mathrm{CVD}^{(1,2)}$. In India, hypertension contributes to $10 \%$ of all deaths and is directly responsible for 57 and $24 \%$ of stroke and CHD deaths, respectively $^{(3)}$. Conservative estimates suggest that one in four adults in urban India and one in five adults in rural India have hypertension ${ }^{(4)}$.

Excess dietary $\mathrm{Na}$ or salt intake is an important modifiable risk factor for hypertension ${ }^{(1)}$. Compared with those consuming $\geq 2 \mathrm{~g} \mathrm{Na} / \mathrm{d}$, adults consuming $<2 \mathrm{~g} \mathrm{Na} / \mathrm{d}$ had a $3.5 \mathrm{mmHg}$ lower mean systolic blood pressure (SBP) and $1.8 \mathrm{mmHg}$ lower mean diastolic blood pressure (DBP) ${ }^{(5)}$. However, salt intake around the world ranges from 6.0 to $11.8 \mathrm{~g} / \mathrm{d}$, which is far in excess of the recommended levels $^{(1,6)}$. The WHO recommends a daily $\mathrm{Na}$ intake of $<2 \mathrm{~g}$, or $5 \mathrm{~g} \mathrm{salt} / \mathrm{d}$, for adults ${ }^{(7)}$. The current salt intake among Indian adults is far higher than the recommended level ${ }^{(8-10)}$, ranging between 9 and $12 \mathrm{~g} / \mathrm{d}$, or 3.6 and $4.8 \mathrm{~g}$ $\mathrm{Na} / \mathrm{d}^{(8,11,12)}$.

Key elements of successful dietary salt reduction strategies include public education, people-friendly food labelling, reformulation of processed foods and taxation ${ }^{(13,14)}$. For example, Finland has witnessed a one-third decrease in the average salt intake in the past three decades after implementing strategies such as warning labels on highsalt foods, public education, food procurement policies with $\mathrm{Na}$ standards and voluntary guidelines for limiting $\mathrm{Na}$ in foods. These efforts along with other risk reduction measures have led to a more than $10 \mathrm{mmHg}$ fall in mean 
population SBP and DBP, as well as a $75-80 \%$ decrease in both stroke and CHD mortality ${ }^{(13-15)}$. Further, salt reduction interventions are low cost. For instance, estimates indicate that the cost of implementing a salt reduction programme in South-East Asian countries like India, focused on a $15 \%$ reduction in salt intake by voluntary reduction in processed foods and condiments by the food industry and through consumer education to encourage dietary change using mass media, is between $\$$ US 0.04 and 0.06 per person per year ${ }^{(16,17)}$.

WHO's SHAKE technical package for salt reduction suggests that current understanding on the salt consumption patterns among the population, their knowledge, attitudes and practices related to salt use, and the sources of salt in their diet are important components for the development of effective consumer education and awareness programmes $^{(18)}$. In South Asian countries such as India, the majority of the dietary salt consumed is added during cooking at home or at the table ${ }^{(2,9,11,19)}$. However, limited information is available about population knowledge, attitudes and practices related to the use of salt. In the present paper, we describe knowledge, attitudes and practices regarding salt consumption using data from a representative sample of adults living in rural and urban North India.

\section{Methods}

\section{Participant recruitment}

We did a population survey during March to October 2012 by recruiting a sub-sample of participants from the Centre for Cardiometabolic Risk Reduction in South Asia (CARRS) cohort study in urban Delhi and the Indian Council of Medical Research (ICMR)-funded CVD repeat survey in rural Haryana. The methods, participant recruitment and data collection of the CARRS cohort study and ICMR-funded CVD repeat survey are published in detail elsewhere ${ }^{(20,21)}$. In Delhi, CARRS used a multistage cluster random sampling to recruit participants. Twenty wards or large municipal divisions were selected randomly; five census enumeration blocks (CEB; smaller municipal divisions) per ward, twenty households per $\mathrm{CEB}$ and two adults aged $\geq 20$ years per household were selected randomly. For the current salt substudy, we randomly chose ten wards and two to three CEB per ward (total twenty-five CEB) from the CARRS sample. All the CARRS participants from these CEB were invited to participate. Of the total of 984 invited, 940 consented, 934 were interviewed and 689 provided $24 \mathrm{~h}$ urine samples. In rural Ballabhgarh (Faridabad, Haryana), for the CVD repeat survey, 1250 households were selected from twenty-four villages by simple random sampling and from these households, all adults aged $\geq 30$ years were recruited. For the current salt sub-study, we randomly chose ten villages (from the twenty-four villages) and invited all participants recruited for the CVD repeat survey for the salt sub-study. In addition, individuals (100 participants) aged 20-29 years were recruited from the same households to match with the age group of the urban CARRS study. Of the total 980 participants, 758 consented to participate. Of the 758 , 701 were interviewed and 756 provided $24 \mathrm{~h}$ urine samples. In the present study we used the data of those with complete interview information, comprising 934 and 701 participants, respectively, in the urban and rural areas. The study was approved by the institutional ethics committee and written informed consent was obtained from all participants.

\section{Sample size}

Sample size calculation was based on the primary objective of the study, which was to measure population level of dietary salt intake using $24 \mathrm{~h}$ urine samples. Assuming a mean urinary $\mathrm{Na}$ excretion of $3.9 \mathrm{~g} / \mathrm{d}$ and an $\mathrm{SD}$ of $1.15 \mathrm{~g} / \mathrm{d}^{(22)}$, to detect a $0.2 \mathrm{~g} / \mathrm{d}$ or more difference in $24 \mathrm{~h}$ urinary $\mathrm{Na}$ excretion between the four strata (rural men; rural women; urban men; urban women) with $90 \%$ power and $\alpha$ of 0.05 , a sample of 263 was needed in each stratum. Taking into consideration a non-response rate (refusal to provide $24 \mathrm{~h}$ urine sample) of $30 \%$, the sample size in each of the stratum was 342 , which we rounded off to 350 . We invited all the participants selected for the survey. Assuming that $50 \%$ of the participants had correct knowledge, attitudes and practices related to salt consumption, the available samples of 934 and 701 in urban and rural areas would have a power of 86 and $76 \%$, respectively, at an $\alpha$ of 0.05 and an acceptable difference in proportions of $5 \%$.

\section{Data collection}

A standardised questionnaire was administered to each participant for obtaining information on demographic characteristics, medical history, tobacco and alcohol use, use of medication and physical activity. The questions about knowledge, attitudes and practices were adapted from the WHO/Pan American Health Organization protocol for population-level Na determination $^{(23)}$. The questionnaire consisted of questions on: (i) knowledge of the health effects of high salt consumption, i.e. whether participants knew that high salt consumption could cause health problem/s, the specific health problem $/ \mathrm{s}$ and the maximum limit of daily salt consumption (whether they knew there is a limit for daily salt consumption and if so, what the limit is); (ii) attitudes, i.e. perceived level of daily salt consumption and attitude towards reducing the daily salt consumption; and (iii) practices, i.e. timing of addition of salt during cooking (at the beginning of cooking; halfway through cooking; towards the end of cooking; after cooking), addition of salt in rice/dough, addition of salt to food/salad at the table or while eating, regular actions taken to reduce daily salt consumption and what actions they actually do to reduce their daily salt consumption (avoid/minimise consumption of snacks/ namkeens/pickles/papads/processed foods; look at the salt labels on food; do not add salt at the table; buy lowsalt alternatives; do not add salt when cooking; use spices other than salt when cooking; avoid eating out). We 
defined participants' perception to reduce daily salt consumption as positive if they responded that it was 'somewhat' or 'very important' to reduce dietary salt when asked, 'How important to you is lowering the salt in your diet?' We also stratified participants as taking action to reduce salt if they responded 'yes' to the question, 'Do you do anything on a regular basis to control dietary salt intake?'

Weight and height were measured using a portable bioimpedance-measuring device (TANITA-BC601) and a portable stadiometer (SECA-214) to the nearest $0 \cdot 1 \mathrm{~kg}$ and $0 \cdot 1 \mathrm{~cm}$, respectively. BMI was calculated as weight divided by the square of height: [weight $(\mathrm{kg})] /\left[\right.$ height $\left(\mathrm{m}^{2}\right)$ ]. BMI $<25.0 \mathrm{~kg} / \mathrm{m}^{2}$ was categorised as normal weight and BMI $\geq 25 \cdot 0 \mathrm{~kg} / \mathrm{m}^{2}$ as overweight or obesity ${ }^{(24)}$.

Blood pressure was measured twice after 5 min of resting in a seated position, using a validated automated digital oscillometric sphygmomanometer (OMRON-HEM7080). The readings were repeated at $1 \mathrm{~min}$ interval. A third reading was taken if the difference between the first and second readings was $\geq 10 \mathrm{mmHg}$ or $\geq 6 \mathrm{mmHg}$ for SBP or DBP, respectively. The mean of the last two readings was taken for defining blood pressure. Blood pressure was stratified as 'known hypertension' if self-reported hypertension (irrespective of treatment); 'new hypertension' if measured SBP/DBP was $\geq 140 / 90 \mathrm{mmHg}$; 'pre-hypertension' if measured SBP/DBP was 120-139/ $80-89 \mathrm{mmHg}$; and 'normal' if measured SBP/DBP was $<120 / 80 \mathrm{mmHg}^{(25)}$.

A single $24 \mathrm{~h}$ urine sample was obtained from the participants. They were asked to collect all urine passed during a $24 \mathrm{~h}$ period starting from the second urination on the morning of the collection day and ending with the first urine passed the following morning. Participants were asked to note, on a paper record sheet, the start and finish times of their urine collection as well any missed urine collection/s. If the participant reported duration of collection of $<24 \mathrm{~h}$, more than one void missed or more than one episode of substantial spillage of a void, the collection was deemed incomplete and the participant was offered the option to redo the $24 \mathrm{~h}$ collection. The quantity of collected urine was measured and four aliquots of $1 \mathrm{ml}$ each were prepared for analysis and storage at a central laboratory. Urinary $\mathrm{Na}$ and $\mathrm{K}$ from $24 \mathrm{~h}$ urine samples were determined using direct measurement by ion-selective electrode on an electrolyte analyser (XI-921) and with reagents from Caretium, Shenzhen, China. Unassayed urinary control from RANDOX was used as internal quality control. We excluded samples with urinary creatinine $<4.0 \mathrm{mmol} / \mathrm{d}$ for women, or $<6.0 \mathrm{mmol} / \mathrm{d}$ for men, or a $24 \mathrm{~h}$ urine collection of $<500 \mathrm{ml}$ for either sex. For each participant, the $24 \mathrm{~h} \mathrm{Na}$ excretion value $(\mathrm{g} / \mathrm{d})$ was calculated as the concentration of $\mathrm{Na}$ in the urine $(\mathrm{g} / \mathrm{l})$ multiplied by the urinary volume $(\mathrm{l} / \mathrm{d})$.

\section{Statistical analysis}

For urban samples from CARRS, sampling weights were generated accounting for the multistage cluster random design $^{(20)}$. Since rural households were selected by simple random sampling, we used sampling weight of 1 for all rural participants. The demographic characteristics and knowledge, attitudes and practices about dietary salt intake were summarised as proportions or means, both with 95\% CI, adjusted for the sampling weights. We further assessed the association of sociodemographic characteristics (age, gender, residence (rural/urban) and education), BMI, blood pressure status and participants' knowledge (of hypertension, daily salt limits and the relationship between salt and hypertension) with their perception to reduce daily salt intake (yes/no) using a multivariate logistic regression model adjusted for clustering effect at the household level. We repeated a similar model with action to reduce daily consumption of salt (yes/no) as the outcome. The adjusted OR and 95\% CI of the association were estimated. All statistical analyses were performed using the statistical software package Stata version 12.0.

\section{Results}

Complete data on knowledge, attitudes and practices were available for 934/940 (99.4\%) and 701/757 (92.6\%) of participants in urban Delhi and rural Haryana, respectively. The sociodemographic characteristics of the participants by residence are presented in Table 1 . The mean age of the participants was 45.9 years in the rural areas and 41.8 years in the urban areas. Women constituted 59.6 and $50.2 \%$ in rural and urban samples, respectively. Mean years of education was $5 \cdot 1$ and 8.4 years in the rural and urban samples, respectively. Tobacco and alcohol use were higher among rural compared with urban participants. Fifty-three per cent of urban and $23 \%$ of rural participants were consuming $\leq 5 \mathrm{~g}$ salt/d. The prevalence of hypertension, known and newly diagnosed, was 10.4 and $19.9 \%$ in the rural and 12.0 and $22.3 \%$ in the urban areas, respectively, whereas overweight and obesity (BMI $\geq 25.0 \mathrm{~kg} / \mathrm{m}^{2}$ ) prevalence was 28.1 and $49.3 \%$ in rural and urban areas, respectively.

Participants' knowledge, attitudes and practices towards dietary salt intake are presented in Table 2. Half of the urban participants $(47.9 \%)$ compared with a quarter of the rural participants $(22.7 \%)$ knew one or more adverse health effects of high salt consumption. However, only 17.5 and $20.8 \%$ of rural and urban participants, respectively, knew that there should be a limit for daily salt consumption. Most participants who knew there should be a limit to daily salt consumption, also knew the correct amount of daily consumption $(\leq 1$ teaspoon of salt; 1 teaspoon $\approx 5 \mathrm{~g}$ of salt). Most participants $(75.6 \%$ of rural and $66.5 \%$ of urban) thought that they were eating the right amount of salt. Nearly $46 \%$ of both rural and urban participants reported that it was very or somewhat important to lower salt content in their diet. However, 
Table 1 Sociodemographic characteristics, by residence, of adults aged $\geq 20$ years in rural Haryana and urban Delhi, North India

\begin{tabular}{|c|c|c|c|c|}
\hline \multirow[b]{2}{*}{ Characteristic } & \multicolumn{2}{|c|}{ Rural ( $n$ 701) } & \multicolumn{2}{|c|}{ Urban ( $n$ 934) } \\
\hline & $\%$ or Mean & $95 \% \mathrm{Cl}$ & $\%$ or Mean & $95 \% \mathrm{Cl}$ \\
\hline \multicolumn{5}{|l|}{ Age group $(\% ; n 1635)$} \\
\hline $20-39$ years & $41 \cdot 2$ & $37 \cdot 6,44 \cdot 9$ & $45 \cdot 2$ & $41 \cdot 5,48 \cdot 9$ \\
\hline $40-59$ years & 35.4 & $31.8,38.9$ & $44 \cdot 8$ & $41 \cdot 2,48 \cdot 4$ \\
\hline$\geq 60$ years & $23 \cdot 4$ & $20 \cdot 2,26 \cdot 5$ & $10 \cdot 0$ & $8.4,11.6$ \\
\hline Mean age (years) & 45.9 & $44 \cdot 8,47 \cdot 1$ & 41.8 & $41 \cdot 0,42 \cdot 7$ \\
\hline \multicolumn{5}{|l|}{ Sex $(\% ; n 1635)$} \\
\hline Men & $40 \cdot 4$ & $36 \cdot 7,44 \cdot 0$ & $49 \cdot 8$ & $46 \cdot 2,53 \cdot 5$ \\
\hline Women & $59 \cdot 6$ & $56 \cdot 0,63 \cdot 3$ & $50 \cdot 2$ & $46 \cdot 5,53 \cdot 8$ \\
\hline \multicolumn{5}{|l|}{ Education (\%; $n$ 1635) } \\
\hline $0-4$ years & $49 \cdot 1$ & $45 \cdot 4,52 \cdot 8$ & $21 \cdot 1$ & $18 \cdot 1,24 \cdot 1$ \\
\hline $5-12$ years & $44 \cdot 2$ & $40.5,47.9$ & $57 \cdot 3$ & $53.7,60.9$ \\
\hline$\geq 13$ years & $6 \cdot 7$ & $4.8,8.6$ & $21 \cdot 6$ & $18 \cdot 6,24 \cdot 6$ \\
\hline Mean education (years) & $5 \cdot 1$ & $4 \cdot 7,5 \cdot 5$ & 8.4 & $8.0,8.8$ \\
\hline \multicolumn{5}{|l|}{ Current tobacco use $(\% ; n$ 1632) } \\
\hline Yes & $35 \cdot 8$ & $32 \cdot 2,39.4$ & $22 \cdot 7$ & $19 \cdot 6,25 \cdot 7$ \\
\hline No & $64 \cdot 2$ & $60 \cdot 6,67 \cdot 7$ & $77 \cdot 3$ & $74 \cdot 3,80 \cdot 3$ \\
\hline \multicolumn{5}{|l|}{ Current alcohol use (\%; $n$ 1632) } \\
\hline Yes & $14 \cdot 6$ & $12 \cdot 0,17 \cdot 2$ & $13 \cdot 7$ & $11 \cdot 2,16 \cdot 2$ \\
\hline No & 85.4 & $82 \cdot 8,88 \cdot 0$ & $86 \cdot 3$ & $83 \cdot 8,88 \cdot 8$ \\
\hline \multicolumn{5}{|l|}{ Salt consumption† (\%; $n$ 1390) } \\
\hline$\leq 5 \mathrm{~g} / \mathrm{d}$ & $23 \cdot 0$ & $19 \cdot 8,26 \cdot 1$ & $53 \cdot 0$ & $48 \cdot 8,57 \cdot 2$ \\
\hline$>5 \mathrm{~g} / \mathrm{d}$ & $77 \cdot 0$ & $73 \cdot 9,80 \cdot 2$ & $47 \cdot 0$ & $42 \cdot 8,51 \cdot 2$ \\
\hline Mean salt consumption $(\mathrm{g} / \mathrm{d})$ & $9 \cdot 2$ & $8.8,9.6$ & $5 \cdot 6$ & $5 \cdot 3,5 \cdot 9$ \\
\hline \multicolumn{5}{|l|}{ BMI category (\%; $n$ 1442) } \\
\hline$<25.0 \mathrm{~kg} / \mathrm{m}^{2}$ & $71 \cdot 9$ & $68 \cdot 5,75 \cdot 2$ & $50 \cdot 7$ & $46 \cdot 7,54 \cdot 7$ \\
\hline$\geq 25.0 \mathrm{~kg} / \mathrm{m}^{2}$ & $28 \cdot 1$ & $24 \cdot 8,31.5$ & $49 \cdot 3$ & $45 \cdot 2,53 \cdot 3$ \\
\hline Mean BMI $\left(\mathrm{kg} / \mathrm{m}^{2}\right)$ & $22 \cdot 6$ & $22 \cdot 3,22 \cdot 9$ & $25 \cdot 3$ & $24 \cdot 9,25 \cdot 7$ \\
\hline \multicolumn{5}{|l|}{ Hypertension $\ddagger(\% ; n$ 1632) } \\
\hline Known & $10 \cdot 4$ & $8 \cdot 1,12 \cdot 7$ & $12 \cdot 0$ & $9 \cdot 7,14 \cdot 1$ \\
\hline Newly diagnosed & $19 \cdot 9$ & $16 \cdot 9,22 \cdot 8$ & $22 \cdot 3$ & $19 \cdot 4,25 \cdot 3$ \\
\hline Pre-hypertension & 31.6 & $28 \cdot 1,35 \cdot 0$ & 33.0 & $29 \cdot 6,36 \cdot 4$ \\
\hline Normal & $38 \cdot 1$ & $34.5,41 \cdot 7$ & $32 \cdot 7$ & $29 \cdot 2,36 \cdot 2$ \\
\hline Mean SBP (mmHg) & $122 \cdot 7$ & $121 \cdot 2,124 \cdot 2$ & 123.6 & $122 \cdot 3,125 \cdot 0$ \\
\hline Mean DBP (mmHg) & $81 \cdot 6$ & $80 \cdot 7,82 \cdot 5$ & $83 \cdot 1$ & $82 \cdot 2,84 \cdot 0$ \\
\hline
\end{tabular}

SBP, systolic blood pressure; DBP, diastolic blood pressure.

Data are presented as means for continuous variables or proportions for categorical variables, both with $95 \% \mathrm{Cl}$.

†Estimated from $24 \mathrm{~h}$ urinary $\mathrm{Na}$ excretion.

łKnown hypertension defined as self-reported hypertension (irrespective of treatment); new hypertension defined as measured SBP/DBP $\geq 140 / 90$ mmHg; prehypertension defined as measured SBP/DBP $=120-139 / 80-89 \mathrm{mmHg}$; and normal defined as measured SBP/DBP $<120 / 80 \mathrm{mmHg}$.

more than $70 \%$ of both rural and participants reported always adding salt to dough, rice or food and to salad at the table. Only $3.7 \%$ of rural and $10 \cdot 2 \%$ of urban participants were taking any action to control their dietary salt intake. Some of the measures taken to reduce to reduce salt intake were avoiding eating out, or not adding salt while cooking, or using low-salt alternatives.

The mean salt intake, from $24 \mathrm{~h}$ urinary $\mathrm{Na}$ excretion, among those who reported their own salt consumption as 'too much', 'just right' and 'too little' in both rural and urban areas is presented in Fig. 1. More than $80 \%$ of both rural and urban participants perceived their level of salt consumption as 'just right' or 'too little', while nearly $10 \%$ of participants said that they consume excess amount of salt.

The adjusted odds of perceived importance and selfreported actions to reduce dietary salt consumption are presented in Table 3. Compared with urban participants, more rural participants perceived it is important to reduce dietary salt consumption ( OR $=1.39$; $95 \%$ CI 1.08, 1.79); however, they were less likely to take any action $(\mathrm{OR}=$ 0.35 ; $95 \%$ CI $0.19,0.65$ ). There was no significant difference between age groups in the perception and actions to reduce dietary salt in their diet. Participants with known hypertension were more likely (OR $=3.91 ; 95 \%$ CI 1.74 , 8.77) to take some action to reduce their daily salt consumption compared with others. Those who knew that excess consumption of dietary salt increases blood pressure had higher odds of perceived importance of reducing salt compared with those with no knowledge $(\mathrm{OR}=5.57$; $95 \%$ CI $3 \cdot 29,9 \cdot 43)$ and they were also more likely to take actions to reduce salt consumption ( $\mathrm{OR}=8 \cdot 37$; $95 \% \mathrm{CI}$ $2 \cdot 68,26 \cdot 2)$. Correct knowledge about the daily salt consumption limit was also significantly associated with the importance of reducing salt consumption (OR $=1 \cdot 83 ; 95 \%$ CI $1.32,2.53)$ and action to reduce salt consumption $(\mathrm{OR}=2.63 ; 95 \%$ CI $1.52,4.57)$, compared with those without knowledge. 
Table 2 Knowledge, attitudes and practices regarding dietary salt consumption, by residence, of adults aged $\geq 20$ years in rural Haryana and urban Delhi, North India

\begin{tabular}{|c|c|c|c|c|}
\hline & \multicolumn{2}{|c|}{ Rural ( $n 701)$} & \multicolumn{2}{|c|}{ Urban ( $n$ 934) } \\
\hline & $\%$ & $95 \% \mathrm{Cl}$ & $\%$ & $95 \% \mathrm{Cl}$ \\
\hline \multicolumn{5}{|l|}{ Knowledge } \\
\hline \multicolumn{5}{|l|}{ Knows high salt diet causes health problems } \\
\hline Yes & $22 \cdot 7$ & $19 \cdot 6,25 \cdot 8$ & 47.9 & $44 \cdot 3,51 \cdot 5$ \\
\hline No & $15 \cdot 7$ & $13 \cdot 0,18 \cdot 4$ & 12.9 & $10.5,15.4$ \\
\hline Don't know & 61.6 & $58 \cdot 0,65 \cdot 2$ & $39 \cdot 2$ & $35 \cdot 6,42 \cdot 7$ \\
\hline \multicolumn{5}{|c|}{ Knows high-salt diet is a risk factor for high blood pressure/hypertension } \\
\hline Yes & $24 \cdot 0$ & $20 \cdot 9,27 \cdot 2$ & $40 \cdot 5$ & $37 \cdot 0,44 \cdot 0$ \\
\hline No & $76 \cdot 0$ & $72 \cdot 9,79 \cdot 2$ & 59.5 & $56 \cdot 0,63 \cdot 0$ \\
\hline \multicolumn{5}{|l|}{ Knows there should be a maximum daily salt consumption limit } \\
\hline Yes & 17.5 & $14 \cdot 7,20 \cdot 4$ & $20 \cdot 8$ & $17 \cdot 8,23 \cdot 8$ \\
\hline No & $61 \cdot 2$ & $57 \cdot 6,64 \cdot 8$ & 23.5 & $20 \cdot 4,26 \cdot 8$ \\
\hline Don't know & $21 \cdot 3$ & $18 \cdot 2,24 \cdot 3$ & $55 \cdot 8$ & $52 \cdot 2,59 \cdot 4$ \\
\hline \multicolumn{5}{|l|}{ Knows correct amount of daily salt consumption† } \\
\hline Yes & $17 \cdot 4$ & $14 \cdot 6,20 \cdot 2$ & $17 \cdot 9$ & $15 \cdot 1,20 \cdot 8$ \\
\hline No & 82.5 & $79 \cdot 6,85 \cdot 3$ & 80.4 & $77.5,83.4$ \\
\hline Don't know & 0.1 & $-0.1,0.4$ & 1.6 & $0.6,2.6$ \\
\hline \multicolumn{5}{|l|}{ Attitudes } \\
\hline \multicolumn{5}{|l|}{ Thinks s/he is eating: } \\
\hline Too much salt & $9 \cdot 1$ & $6 \cdot 9,11 \cdot 1$ & $11 \cdot 8$ & $9 \cdot 3,14 \cdot 2$ \\
\hline Just the right amount salt & $75 \cdot 6$ & $72 \cdot 4,78.8$ & 66.5 & $63 \cdot 1,70 \cdot 0$ \\
\hline Too little salt & $15 \cdot 3$ & $12 \cdot 6,18 \cdot 0$ & $17 \cdot 4$ & $14 \cdot 7,20 \cdot 1$ \\
\hline Don't know & 0.0 & & 4.3 & $2 \cdot 8,5 \cdot 7$ \\
\hline \multicolumn{5}{|l|}{ Thinks it is important to lower dietary salt consumption } \\
\hline Yes & $46 \cdot 6$ & $43 \cdot 0,50 \cdot 3$ & $45 \cdot 1$ & $41 \cdot 5,48 \cdot 7$ \\
\hline No & $49 \cdot 1$ & $45 \cdot 4,52 \cdot 8$ & $26 \cdot 1$ & $22 \cdot 9,29 \cdot 3$ \\
\hline Don't know & $4 \cdot 3$ & $2 \cdot 8,5 \cdot 8$ & 28.8 & $25 \cdot 5,32 \cdot 2$ \\
\hline \multicolumn{5}{|l|}{ Practices } \\
\hline \multicolumn{5}{|l|}{ Adds salt in cooking } \\
\hline Towards the end/after cooking & 0.6 & $0.0,1 \cdot 1$ & 3.2 & $1.9,4.5$ \\
\hline Halfway through cooking & 1.3 & $0.4,2 \cdot 1$ & $29 \cdot 0$ & $25 \cdot 6,32 \cdot 3$ \\
\hline At the beginning of cooking & $96 \cdot 7$ & $95.4,98.0$ & $55 \cdot 7$ & $52 \cdot 1,59 \cdot 3$ \\
\hline Don't know & 1.4 & $0.5,0.2$ & $12 \cdot 2$ & $9.9,14.5$ \\
\hline \multicolumn{5}{|l|}{ Do you add salt to dough/rice } \\
\hline Always & $98 \cdot 7$ & $97.9,99.6$ & $70 \cdot 1$ & $66 \cdot 8,73.4$ \\
\hline Never & 1.3 & $0.4,2.1$ & 29.9 & $26 \cdot 6,33 \cdot 2$ \\
\hline \multicolumn{5}{|l|}{ Do you add salt to food/salad at the table or while eating } \\
\hline Always & $80 \cdot 6$ & $77 \cdot 7,83 \cdot 5$ & $87 \cdot 6$ & $85 \cdot 3,89 \cdot 9$ \\
\hline Never & 19.4 & $16 \cdot 5,22 \cdot 3$ & $12 \cdot 4$ & $10 \cdot 1,14 \cdot 7$ \\
\hline \multicolumn{5}{|l|}{ Take regular action to control salt intake } \\
\hline Yes & 3.7 & $2 \cdot 3,5 \cdot 1$ & $10 \cdot 2$ & $8 \cdot 0,12 \cdot 3$ \\
\hline \multirow{2}{*}{\multicolumn{5}{|c|}{ Actions taken to control salt intake }} \\
\hline & & & & \\
\hline $\begin{array}{l}\text { Avoid/minimise consumption of snacks/namkeens/pickles/ } \\
\text { papads/processed foods }\end{array}$ & 0.4 & $-0.0,0.9$ & 0.9 & $0.3,1.4$ \\
\hline Look at the salt labels on food/buy low-salt alternatives & 0.6 & $0.0,1 \cdot 1$ & 3.0 & $1 \cdot 7,4.3$ \\
\hline Do not add salt at the table/cooking & $2 \cdot 6$ & $1 \cdot 4,3 \cdot 7$ & $2 \cdot 7$ & $1 \cdot 7,3.7$ \\
\hline Use spices other than salt when cooking & 0.0 & & 0.5 & $-0.0,0.1$ \\
\hline Avoid eating out & 0.1 & $-0.1,0.4$ & 3.0 & $1 \cdot 8,4 \cdot 3$ \\
\hline No action taken & $96 \cdot 3$ & $94.9,97 \cdot 7$ & 89.9 & $87 \cdot 7,92 \cdot 0$ \\
\hline
\end{tabular}

†Correct amount: $\leq 1$ teaspoon of salt (1 teaspoon $\approx 5 \mathrm{~g}$ of salt).

\section{Discussion and conclusion}

Our study assessed the knowledge, attitudes and practices regarding use of salt in the diet of a representative sample of adults living in rural and urban areas of North India. We found low levels of knowledge regarding the adverse health effects of excess salt consumption and recommended daily intake of salt for a person, especially among rural participants. The majority of both rural and urban participants reported that their salt consumption level was 'just right', whereas only a small proportion actually met the recommended consumption level of $\leq 5 \mathrm{~g}$ salt $/ \mathrm{d}$. Overall, the knowledge, attitudes and practices towards daily salt intake were worse in rural areas than in urban areas.

The knowledge about the adverse effects of excess salt consumption on health was poorer among rural participants compared with urban participants. Those who had knowledge of the recommended daily allowance of salt and of excess salt's effect on blood pressure were more likely to express interest to reduce dietary salt intake and reported taking one or more actions to reduce dietary salt. 


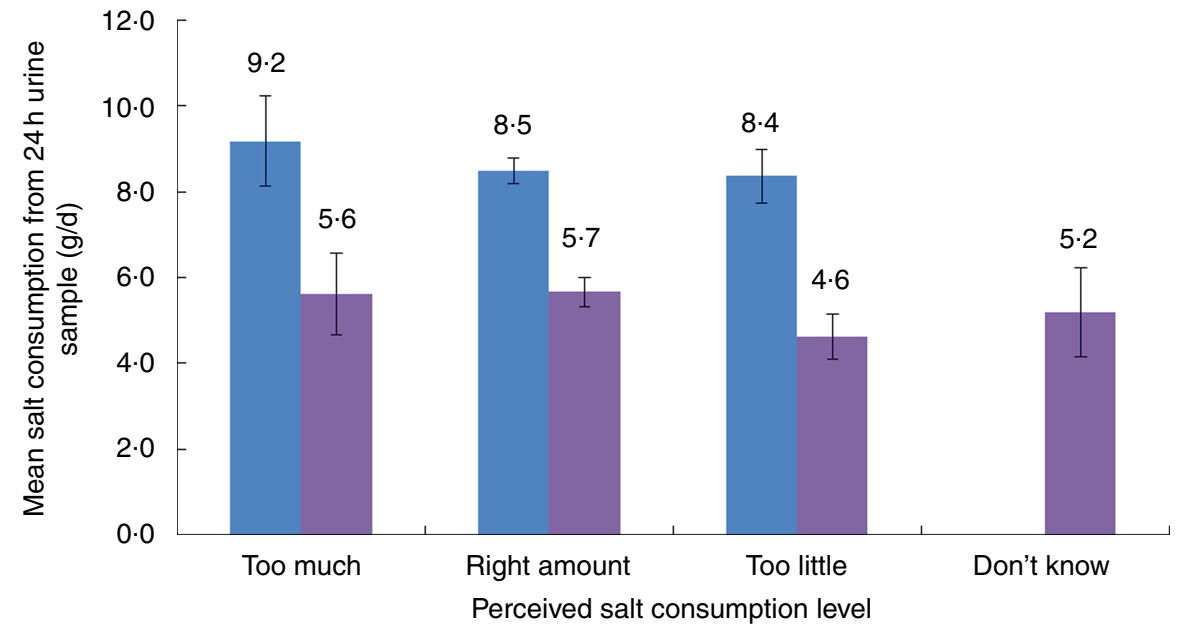

Fig. 1 (colour online) Comparison of mean salt consumption, estimated from $24 \mathrm{~h}$ urinary sodium excretion, according to perceived salt consumption level among adults aged $\geq 20$ years in rural Haryana $(\square)$ and urban Delhi $(\square)$, North India. Measured mean salt consumption reported as $\mathrm{g} / \mathrm{d}$, with $95 \% \mathrm{Cl}$ represented by vertical bars, and perceived salt consumption level as percentages: $9.1 \%$ of rural and $11.8 \%$ of urban participants reported too high salt intake; $75.6 \%$ of rural and $66.5 \%$ of urban participants reported right amount of salt intake; and $15.3 \%$ of rural and $17.4 \%$ of urban participants reported too little salt intake

Table 3 Factors associated with perceived importance and self-reported actions to reduce dietary salt consumption, using multivariate logistic regression models, among adults $(n 1437)$ aged $\geq 20$ years in rural Haryana and urban Delhi, North India

\begin{tabular}{|c|c|c|c|c|c|c|}
\hline & \multicolumn{3}{|c|}{$\begin{array}{l}\text { Perceived importance to reduce dietary } \\
\text { salt consumption }\end{array}$} & \multicolumn{3}{|c|}{$\begin{array}{l}\text { Take action (self-reported) to reduce dietary } \\
\text { salt consumption }\end{array}$} \\
\hline & $\%$ & Adjusted OR† & $95 \% \mathrm{Cl}$ & $\%$ & Adjusted OR† & $95 \% \mathrm{Cl}$ \\
\hline \multicolumn{7}{|l|}{ Age group } \\
\hline 20-39 years & $45 \cdot 4$ & 1.00 & Ref. & 4.5 & 1.00 & Ref. \\
\hline $40-59$ years & $48 \cdot 8$ & 1.01 & $0.77,1.31$ & 9.4 & 1.51 & $0.83,2.74$ \\
\hline$\geq 60$ years & $47 \cdot 1$ & 0.86 & $0.61,1.20$ & $11 \cdot 6$ & $1 \cdot 81$ & $0.90,3.62$ \\
\hline \multicolumn{7}{|l|}{ Sex } \\
\hline Men & 51.8 & 1.00 & Ref. & 8.5 & 1.00 & Ref. \\
\hline Women & $43 \cdot 2$ & $0.68^{\star \star}$ & $0.53,0.88$ & 7.5 & 0.85 & $0.53,1.39$ \\
\hline \multicolumn{7}{|l|}{ Type of residence } \\
\hline Urban & $47 \cdot 3$ & 1.00 & Ref. & $11 \cdot 1$ & 1.00 & Ref. \\
\hline Rural & $46 \cdot 9$ & $1 \cdot 39^{\star}$ & $1 \cdot 08,1 \cdot 79$ & 3.7 & $0.35^{\star \star \star}$ & $0.19,0.65$ \\
\hline Mean years of education & $7 \cdot 7$ & 0.98 & $0.96,1.01$ & $9 \cdot 1$ & 0.98 & $0.93,1.03$ \\
\hline \multicolumn{7}{|l|}{ BMI category } \\
\hline$<25.0 \mathrm{~kg} / \mathrm{m}^{2}$ & $45 \cdot 2$ & 1.00 & Ref. & $6 \cdot 3$ & 1.00 & Ref. \\
\hline$\geq 25.0 \mathrm{~kg} / \mathrm{m}^{2}$ & $50 \cdot 4$ & $1 \cdot 16$ & $0.90,1.49$ & $10 \cdot 0$ & 0.91 & $0.54,1.54$ \\
\hline \multicolumn{7}{|l|}{ Blood pressure status } \\
\hline Normal & 43.0 & 1.00 & Ref. & 4.5 & 1.00 & Ref. \\
\hline Known hypertension & $56 \cdot 5$ & 1.45 & $0.88,2.39$ & 21.5 & $3 \cdot 91^{\star * *}$ & $1.74,8.77$ \\
\hline New hypertension & $48 \cdot 7$ & $1 \cdot 15$ & $0.83,1.60$ & $5 \cdot 1$ & 1.02 & $0.48,2.17$ \\
\hline Pre-hypertension & $46 \cdot 7$ & 0.94 & $0.70,1.25$ & $8 \cdot 1$ & 1.35 & $0.70,2.60$ \\
\hline \multicolumn{7}{|l|}{ Knows what hypertension is } \\
\hline No & $35 \cdot 1$ & 1.00 & Ref. & $2 \cdot 1$ & 1.00 & Ref. \\
\hline Yes & $63 \cdot 1$ & 0.72 & $0.42,1.24$ & $15 \cdot 7$ & 0.71 & $0.21,2.41$ \\
\hline \multicolumn{7}{|c|}{ Knows the daily limit of salt intake } \\
\hline No & $42 \cdot 8$ & 1.00 & Ref. & 5.9 & 1.00 & Ref. \\
\hline Yes & $67 \cdot 1$ & $1.83^{\star \star \star}$ & $1 \cdot 32,2.53$ & $17 \cdot 7$ & $2 \cdot 63^{\star \star \star}$ & $1.52,4.57$ \\
\hline \multicolumn{7}{|c|}{ Knows that excess salt increases blood pressure } \\
\hline No & $35 \cdot 2$ & 1.00 & Ref. & 2.5 & 1.00 & Ref. \\
\hline Yes & $69 \cdot 0$ & $5 \cdot 57^{\star \star \star}$ & $3.29,9.43$ & $18 \cdot 1$ & $8 \cdot 37^{\star \star \star}$ & $2 \cdot 68,26 \cdot 2$ \\
\hline \multicolumn{7}{|c|}{ Self-reported excess consumption of salt } \\
\hline No & $46 \cdot 8$ & 1.00 & Ref. & $8 \cdot 2$ & 1.00 & Ref. \\
\hline Yes & 49.7 & 1.03 & $0.69,1.51$ & $5 \cdot 6$ & 0.96 & $0.41,2.27$ \\
\hline
\end{tabular}

Ref., reference category.

${ }^{\star} P<0.05,{ }^{\star \star} P<0.01,{ }^{\star \star \star} P<0.001$

†Adjusted for sociodemographic characteristics (age, gender, residence (rural/urban) and education), BMI, blood pressure status and participants' knowledge (of hypertension, salt limits and the relationship between salt and hypertension). 
Similar to findings reported from other studies ${ }^{(2,8,26,27)}$, the majority of the participants in our study also reported that the most important actions to be adopted to control dietary salt intake were avoiding eating out of home, not adding salt during cooking and using low-salt alternatives. Notably, a small proportion suggested the avoidance or reduction in consumption of pickles/papads/namkeens, reading labels on packaged food and not adding salt at the table. These observations are consistent with the results of another cross-sectional study conducted by Johnson et al. in the same region during 2015-16 $6^{(8)}$. Studies from other countries have reported similarly low levels of knowledge on adverse effects of excess salt consumption. For instance, a 2012 population-based study conducted among adults in eleven regions in Xuzhou Province of China also reported that less than third of the population had knowledge of the national recommendations for salt intake and that excessive intake causes high blood pressure $^{(28)}$.

The majority of the participants, specifically from rural areas, perceived that they consumed an adequate amount of salt. The tendency of individuals to perceive their diet quality as good has been reported in other studies as well ${ }^{(2,9)}$. This perception might be a barrier for initiating action to lower salt consumption ${ }^{(8,11,19,29,30)}$, and needs to be factored in while developing public educational programmes for salt reduction.

Lack of understanding/awareness of the main sources of salt in their diet and of strategies to reduce salt may have resulted in the estimated high salt consumption $(7 \cdot 3 \mathrm{~g} / \mathrm{d})$ in the study population. To reduce dietary salt consumption, it is crucial to identify the major sources of salt from the diet. In the Indian context, where most salt is added during cooking or at the table ${ }^{(11)}$, changes at household level in the use of salt could be one of the strategies to reduce high salt intake.

Most of the rural participants in our study followed dietary practices (e.g. adding salt to dough, rice and salads and at the table while eating) that may result in high salt consumption. A similar finding was also reported from a household survey of 5127 individuals in Punjab, India, where more rural respondents (15.6\%) reported always/ often adding salt before cooking/when eating rice/chapattis/vegetables/salads compared with urban respondents $(9 \cdot 1 \%)^{(9)}$. Both chapattis (Indian bread) and rice are staple foods and constitute the largest portion of a typical Indian diet. The use of salt in these staple foods (chapattis and rice) as well as at the table is not required as they are generally consumed with cooked vegetables or lentils, which already have some amount of salt. Tailored behavioural change communication focusing on these aspects may result in a reduction of salt consumption.

Previous studies done in India have focused mainly on the knowledge of salt intake among hypertensives ${ }^{(29-32)}$ and few studies have reported knowledge of salt intake among the general population ${ }^{(8,19)}$. Patients with hypertension may provide 'teachable moments' for disseminating salt reduction messages to modify their diet, and this may likely contribute to better blood pressure control. Not surprisingly, in our study, participants with known hypertension were more likely to take actions to reduce salt consumption than others. Forty per cent $(-3 \cdot 3$, $83.3 \%)$ of rural and $93.1 \%(83.7,102.5 \%)$ of urban participants who reported having hypertension and were on treatment for hypertension were also taking some action to reduce daily salt consumption as compared with prehypertensive or normotensive individuals.

The findings of the present study have important implications for formulating appropriate strategies to reduce salt consumption in India, where CVD are the most common cause of premature mortality and hypertension is the topmost risk factor for them. Modest reduction in population dietary salt consumption could substantially reduce cardiovascular events and medical costs and therefore should be a public health priority ${ }^{(13,33-37)}$. Enhancing the public's awareness is a necessary first step in any salt reduction effort. This calls for tailored, culturally sensitive awareness campaigns with messages targeting rural populations and populations with low education levels ${ }^{(8,11)}$.

The study had some limitations. First, the knowledge, attitudes and practices towards daily salt consumption were self-reported and therefore are susceptible to information bias. Nevertheless, in-person interviews are one of among the most common methods to collect such data and we used a standard questionnaire and trained the interviewers for standardised non-judgemental data collection. Second, the cross-sectional data collection precludes understanding of temporality of associations. Third, the sample for the sub-study was drawn from two different studies with varied sampling designs. CARRS used multistage cluster random sampling to recruit households, while the ICMR CVD repeat survey used simple random sampling. However, to account for this, we used sampling weights for urban participants in analyses and for both studies we also accounted for household-level clustering in the model. The study did have several strengths. Data were collected from a large representative population. We also assessed discretionary salt use (i.e. during cooking or at the table), which is an important element to determine the main sources of salt consumed by our participants. In addition, the salt consumption was estimated using the gold standard method of $24 \mathrm{~h}$ urine sample collection.

Overall, the present study findings indicate low levels of awareness of the adverse effects of excess salt consumption and possible strategies to reduce salt consumption, specifically in rural areas, where hypertension is rising. Tailored public education for salt reduction is imperative, with a particular focus on rural residents. This should be supplemented with ongoing surveillance of salt consumption and population knowledge, attitudes and 
practices, to monitor and maintain the effectiveness of such educational efforts.

\section{Acknowledgements}

Acknowledgements: The authors thank the funding agencies for support, the participants of the CARRS and ICMR CVD studies (within which this study was nested) and the dedicated field research team. Financial support: This work was supported by a sub-grant from the Wellcome Trust Capacity Strengthening Strategic Award to the Public Health Foundation of India and a consortium of UK universities to S.M. The CARRS study was funded by the National Institutes of Health/National Heart, Lung, and Blood Institute (contract number HHSN2682009900026C). R.S. was supported by a Wellcome Trust Capacity Strengthening Strategic Award Extension Phase to the Public Health Foundation of India and a consortium of UK universities (grant number WT084754/Z/08/A). The funders had no role in the design, analysis or writing of this article. Conflict of interest: There are no conflicts of interest to report. Authorship: V.G., R.S. and S.M. conceived the research study. All authors contributed to developing the research study. D.K. and S.G. conducted the analysis for the paper. V.G. drafted the paper with support from R.S. and S.M. All authors reviewed, provided feedback and approved the final version of the paper. Ethics of human subject participation: This study was conducted according to the guidelines laid down in the Declaration of Helsinki and all procedures involving human subjects were approved by the Institutional Review Board of the Public Health Foundation of India, Gurugram, Haryana, India. Written informed consent was obtained from all participants.

\section{References}

1. Brown IJ, Tzoulaki I, Candeias V et al. (2009) Salt intakes around the world: implications for public health. Int J Epidemiol 38, 791-813.

2. Subasinghe AK, Arabshahi S, Busingye D et al. (2016) Association between salt and hypertension in rural and urban populations of low to middle income countries: a systematic review and meta-analysis of population based studies. Asia Pac J Clin Nutr 25, 402-413.

3. Gupta R (2004) Trends in hypertension epidemiology in India. J Hum Hypertens 18, 73-78.

4. Anchala R, Kannuri NK, Pant H et al. (2014) Hypertension in India: a systematic review and meta-analysis of prevalence, awareness, and control of hypertension. J Hypertens 32, $1170-1177$

5. Aburto NJ, Ziolkovska A, Hooper L et al. (2013) Effect of lower sodium intake on health: systematic review and metaanalyses. BMJ 346, f1326.

6. Kotchen TA (2005) Contributions of sodium and chloride to NaCl-induced hypertension. Hypertension 45, 849-850.

7. World Health Organization (2012) Guideline: Sodium Intake for Adults and Children. Geneva: WHO.
8. Johnson C, Mohan S, Rogers K et al. (2017) The association of knowledge and behaviours related to salt with 24-h urinary salt excretion in a population from North and South India. Nutrients 9, E144.

9. Tripathy JP, Thakur JS, Jeet G et al. (2016) Urban rural differences in diet, physical activity and obesity in India: are we witnessing the great Indian equalisation? Results from a cross-sectional STEPS survey. BMC Public Health 16, 816.

10. Ravi S, Bermudez OI, Harivanzan V et al. (2016) Sodium intake, blood pressure, and dietary sources of sodium in an adult South Indian population. Ann Glob Health 82, 234-242.

11. Dhemla S \& Varma K (2015) Salt intake in India - an alarming situation. Int J Food Agric Vet Sci 5, 1-10.

12. Johnson C, Praveen D, Pope A et al. (2017) Mean population salt consumption in India: a systematic review. $J$ Hypertens 35, 3-9.

13. Trieu K, Neal B, Hawkes C et al. (2015) Salt reduction initiatives around the world - a systematic review of progress towards the global target. PLoS One 10, e0130247.

14. He FJ, Li J \& Macgregor GA (2013) Effect of longer term modest salt reduction on blood pressure: Cochrane systematic review and meta-analysis of randomised trials. BMJ 346, f1325.

15. Cobb LK, Appel LJ \& Anderson CAM (2012) Strategies to reduce dietary sodium intake. Curr Treat Options Cardiovasc Med 14, 425-434.

16. Mohan S \& Prabhakaran D (2013) Review of Salt and Health: Situation in South-East Asia Region. New Delhi: WHO South East Asia Regional Office.

17. World Health Organization (2012) Expert Meeting on Population Sodium Reduction Strategies for Prevention and Control of Noncommunicable Disease in the South-East Asia Region. New Delhi: WHO South East Asia Regional Office

18. World Health Organization (2016) The SHAKE Technical Package for Salt Reduction. http://apps.who.int/iris/bitst ream/handle/10665/250135/9789241511346eng.pdf?sequence $=1$ (accessed September 2018)

19. Sarmugam R \& Worsley A (2014) Current levels of salt knowledge: a review of the literature. Nutrients $\mathbf{6}$, 5534-5559.

20. Nair M, Ali MK, Ajay VS et al. (2012) CARRS Surveillance study: design and methods to assess burdens from multiple perspectives. BMC Public Health 12, 701.

21. Prabhakaran D, Roy A, Praveen PA et al. (2017) 20-Year trend of CVD risk factors: urban and rural national capital region of India. Glob Heart 12, 209-217.

22. Jan RA, Shah S, Saleem SM et al. (2006) Sodium and potassium excretion in normotensive and hypertensive population in Kashmir. J Assoc Physicians India 54, 22-26.

23. World Health Organization/Pan American Health Organization Regional Expert Group for Cardiovascular Disease Prevention through Population-wide Dietary Salt Reduction (2010) Protocol for Population Level Sodium Determination in 24- Hour Urine Samples. Geneva: WHO.

24. Chittaranjan S \& Yajnik JSY (2004) Appropriate body-mass index for Asian populations and its implications for policy and intervention strategies. Lancet 363, 157-163.

25. James PA, Oparil S, Carter BL et al. (2014) 2014 evidencebased guideline for the management of high blood pressure in adults: report from the panel members appointed to the Eighth Joint National Committee (JNC 8). JAMA 311, 507-520.

26. Sanchez G, Pena L, Varea S et al. (2012) Knowledge, perceptions, and behavior related to salt consumption, health, and nutritional labeling in Argentina, Costa Rica, and Ecuador. Rev Panam Salud Publica 32, 259-264. 
27. Land M-A, Webster J, Christoforou A et al. (2014) The association of knowledge, attitudes and behaviours related to salt with 24-hour urinary sodium excretion. Int J Behav Nutr Phys Act 11, 47.

28. Li T, Qin Y, Lou P et al. (2015) Salt intake and knowledge of salt intake in a Chinese population: a crosssectional study. Intern Med 5, 186.

29. Kamran A, Azadbakht L, Sharifirad G et al. (2014) Sodium intake, dietary knowledge, and illness perceptions of controlled and uncontrolled rural hypertensive patients. Int $J$ Hypertens 2014, 245480.

30. Parmar P, Rathod GB, Rathod S et al. (2014) Study of knowledge, attitude and practice of general population of Gandhinagar towards hypertension. Int J Curr Microbiol Appl Sci 3, 680-685.

31. Radhika G, Sathya RM, Sudha V et al. (2007) Dietary salt intake and hypertension in an urban south Indian population - [CURES - 53]. J Assoc Physicians India 55, 405-411.
32. Kodali V, Kodavanti MR, Tripuraribhatla PK et al. (1999) Dietary factors as determinants of hypertension: a case control study in an urban Indian population. Asia Pac J Clin Nutr 8, 184-189.

33. Frisoli TM, Schmieder RE, Grodzicki T et al. (2012) Salt and hypertension: is salt dietary reduction worth the effort? $\mathrm{Am} \mathrm{J}$ Med 125, 433-439.

34. He FJ, Burnier M \& Macgregor GA (2011) Nutrition in cardiovascular disease: salt in hypertension and heart failure. Eur Heart J 32, 3073-3080.

35. Thomas MC, Moran J, Forsblom C et al. (2011) The association between dietary sodium intake, ESRD, and all-cause mortality in patients with type 1 diabetes. Diabetes Care $\mathbf{3 4}$, 861-866.

36. Bibbins-Domingo K, Chertow GM, Coxson PG et al. (2010) Projected effect of dietary salt reductions on future cardiovascular disease. $N$ Engl J Med 362, 590-599.

37. Alderman MH (2006) Evidence relating dietary sodium to cardiovascular disease. J Am Coll Nutr 25, 3 Suppl., 256S-261S. 